\title{
Aprendizagem e inovação na indústria farmacêutica indiana: o papel da IFI e outras intervenções políticas ${ }^{1}$
}

DOI: 10.3395/reciis.v2i2.192pt

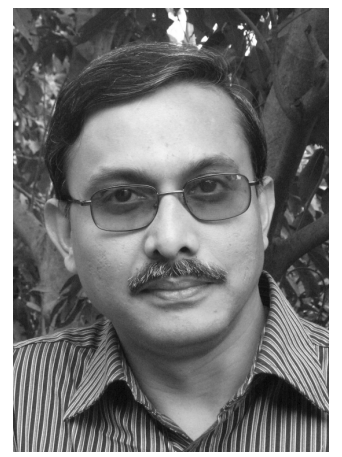

\author{
Amit Showon Ray \\ ICRIER e Jawaharlal Nehru University, Nova Deli, Índia \\ amit.shovon.ray@gmail.com
}

\begin{abstract}
Resumo
Durante as décadas de 1970 e 1980, a indústria farmacêutica indiana (IFI) atingiu patamares impressionantes de maturidade tecnólogica. Na conjuntura atual, porém, a indústria se encontra tentando enfrentar os desafios da globalização e reformas. Ela está passando por uma fase turbulenta de ajuste orientada pela ordem econômica internacional emergente da Organização Mundial do Comércio, especialmente o contrato TRIPS estabelecendo um novo ambiente IFI. O objetivo deste trabalho é explorar a trajetória da aprendizagem e inovação na IFI conforme ela evoluiu através das diversas fases do ambiente político de governo e regimes IFI. Nós concluímos que embora a Índia tenha atingido patamares impressionantes de maturidade tecnológica na indústria farmacêutica, ela ainda tem que chegar às fronteiras globais da pesquisa de ponta de descoberta de medicamentos. Isto somente pode ser alcançado através do esforço tecnológico sustentado e pesquisa e desenvolvimento contínuos.
\end{abstract}

\section{Palavras-chave}

inovação e aprendizagem tecnológica; indústria farmacêutica indiana

\section{Introdução}

A indústria farmacêutica indiana (IFI) ocupa uma posição importante tanto nacional quanto internacionalmente. A Índia está classificada em $13^{\circ}$ entre os países do mundo produtores de medicamentos em termos de valor e em $4^{\circ}$ lugar em termos de volume, com uma participação de $8 \%$ na produção farmacêutica global. ${ }^{2} \mathrm{O}$ tamanho da IFI se expandiu fenomenalmente de meros 100 milhões de rúpias (valor da produção) em 1947 para 50 bilhões de rúpias em 1990 e para sólidos 500 bilhões de rúpias atualmente. ${ }^{3}$ As origens da indústria farmacêutica na Índia remontam à era colonial (pré-independência). Mas direto da sua origem até as décadas de 1950 e 1960, a indústria permaneceu amplamente dominada por firmas estrangeiras e os preços dos medicamentos estavam entre os mais altos no mundo (Relatório do Comitê Kafeveur de 1962).

A década de 1970 foi de grande importância para a IFI, que testemunhou uma "revolução do processo" através de um esforço combinado na aquisição da capacidade tecnológica incentivada por um ambiente de política favorável, especialmente um regime de patente 
fraco. Durante as décadas de 1970 e 1980, a IFI atingiu novos patamares para "liquidar rapidamente" qualquer novo medicamento com um processo não violador e comercializá-los a preços baixos. Na conjuntura atual, porém, a indústria se encontra em uma linha divisória, tentando enfrentar os desafios da globalização e reformas. Ela está passando por uma fase turbulenta de ajuste orientada pela ordem econômica internacional emergente da OMC, especialmente o contrato TRIPS estabelecendo um novo ambiente IFI.

O objetivo deste trabalho é explorar a trajetória da aprendizagem e inovação na IFI conforme ela evoluiu através das diversas fases do ambiente político de governo e regimes IFI. Começaremos com uma discussão sobre a mudança de paradigma na estrutura e desempenho da indústria farmacêutica indiana na forma de "revolução do processo" após a década de 1970. Isto estabelece o estágio para uma discussão detalhada da nova ordem econômica internacional após a década de 1990 na medida em que ela impacta o setor farmacêutico. Tentaremos também analisar os desafios impostos pela nova ordem e os conseqüentes ajustes na indústria.

\section{Revolução do processo na indústria farmacêutica indiana após a década de 1970}

A década de 1970 marcou o início de uma nova era para a indústria farmacêutica na Índia. Com a introdução da Lei de Patentes de 1970, havia um esforço concentrado na geração de capacidade tecnológica nativa (tanto na produção, quanto na pesquisa) no setor farmacêutico com o objetivo de aumentar o acesso aos medicamentos a custos acessíveis. De fato, a década de 1970 testemunhou a passagem de diversas diretivas governamentais moldando o caminho do crescimento deste setor, incluindo as Ordens de Controle de Preço de Medicamentos (DPCO) de 1970 e 1979, a Lei de Regulação de Câmbio Estrangeiro (FERA) de 1973, a Nova Política de Medicamentos de 1978 e, evidentemente, a Lei de Patentes de 1970.

A Lei de Patentes de 1970 foi uma partida radical da lei inicial, que conferia proteção à patente de produto assim como à patente do processo por um período de dez anos (prorrogáveis por outros seis anos) e atuou como um impedimento principal à criação de capacidade tecnológica nativa, especialmente através da engenharia reversa. A Lei de Patentes de 1970, em comparação, conferiu apenas a patente do processo para as substâncias químicas, incluindo produtos farmacêuticos, reduziu a duração das patentes para sete anos a partir da data do protocolo ou cinco anos a partir da data da selagem, o que fosse menor, excluídas todas as substâncias importadas do domínio da proteção de patentes (isto é, somente novas substâncias fabricadas na Índia tinham direito à proteção de patentes), e colocavam o ônus da prova sobre o autor, em caso de infração.

ADPCO de 1970 foi o primeiro esforço concentrado e racional para verificar o contínuo aumento dos preços de medicamentos na Índia. A DPCO de 1979 expandiu a cobertura do controle de preços dos medicamentos, tra- zendo cerca de $80 \%$ da indústria farmacêutica indiana (em termos de valor) sob regulação de preços. Foram criadas normas definidoras de preço mais rígidas e severas.

A FERA de 1973 foi introduzida para restringir e regular as operações de empresas estrangeiras (multinacionais) na Índia para proteger e desenvolver capacidades industriais e tecnológicas nativas. Um teto de 40\% foi imposto sobre o capital estrangeiro, com a exceção dos setores "essenciais" (incluindo produtos farmacêuticos), onde até $74 \%$ do capital estrangeiro foi permitido para produtores de formulação e grande quantidade de alta tecnologia, desde que $50 \%$ do volume sejam fornecidos para formuladores não associados e a parcela do grande volume próprio em sua formulação não deve ultrapassar $1 / 5$.

O espírito do regime desta política dos anos 1970 foi reforçado pela Política de Medicamentos de $1978 \mathrm{com}$ seu objetivo triplo da autoconfiança na tecnologia farmacêutica, auto-suficiência na produção de medicamentos e disponibilidade fácil e barata de medicamentos. Isto, de uma forma, resume a estrutura da política adotada nos anos 1970 com uma ênfase clara na substituição da importação e autoconfiança na produção de grande volume, assim como das formulações, e na criação de capacidade tecnológica nativa do desenvolvimento do processo (grande volume).

Contra o pano de fundo deste ambiente de política, a indústria farmacêutica na Índia embarcou em uma nova trajetória de aprendizagem tecnológica baseada na engenharia reversa, que essencialmente implica a decodificação de um processo original para a produção de um medicamento em grande quantidade. Isto envolve uma compreensão detalhada das propriedades químicas da molécula ativa, os excipientes usados e o processo químico de conversão a partir do composto molecular ativo para o medicamento final em grande quantidade. Um processo químico incorpora um conjunto complexo de parâmetros, como, por exemplo, condições do solvente, temperatura, tempo, métodos para mexer, uso de diversas substâncias químicas e físicas com diferentes níveis de pureza etc., sendo que todos têm que ser otimizados simultaneamente a fim de chegar à especificação do processo ideal. É possível decodificar todas estas especificações paramétricas de um processo através da engenharia reversa.

Uma pessoa pode fazer uma distinção entre dois tipos de atividades de engenharia reversa: processos violadores e não-violadores. No caso do primeiro, um processo com engenharia reversa combina exatamente as especificações e o projeto do processo original e, portanto, nem é preciso mencionar que o uso de tais processos viola os direitos de propriedade intelectual do processo original. Consequentemente, o escopo de tais atividades está limitado apenas às drogas sem patente. A segunda categoria de atividades de engenharia reversa é algo mais complexo, pois ela resulta no desenvolvimento de processos não-violadores, pelos quais o mesmo medicamento, em grande volume, pode ser produzido através de um caminho distinto. Os processos não-violadores são relevantes apenas no caso de drogas patenteadas, que podem não apresentar patentes de produtos, mas continuar a usufruir de proteção de patente de processo. 
Com a introdução da Lei de Patentes de 1970, houve o amplo desenvolvimento da engenharia reversa para processos não-violadores. Isto não sugere que o desenvolvimento de processos violadores (simples imitação) não ocorreu. De fato, muitas das firmas começaram com tais atividades tecnológicas simples (talvez sobre medicamentos sem patente) para adquirir capacidades mais complexas em um estágio posterior. Com certeza, a indústria adquiriu substancial capacidade tecnológica de desenvolvimento de processos através da engenharia reversa, ambos os processos infratores para moléculas sem patente e processos não infratores para moléculas patenteadas. Este fenômeno foi, com frequência, denominado a revolução do processo na indústria farmacêutica indiana. Em decorrência disto, a indústria de medicamentos de grande volume cresceu a uma taxa fenomenalmente alta de 21 e $11 \%$ ao ano durante as décadas de 1970 e 1980 , respectivamente.

Junto com a revolução do processo, o simples desenvolvimento de produtos em formas de dosagem convencionais, que já tinha começado na era pós-independência, continuou após os anos 1970. Como resultado, a indústria da formulação também registrou índices de crescimento impressionantes de 13 e $10 \%$ ao ano, respectivamente, durante os mesmos períodos. O ímpeto veio em grande parte da expansão mássica dos medicamentos em grande volume devido à revolução do processo e políticas para impedir o consumo cativo de grande volume.

Com certeza houve um aumento marcado nos gastos em pesquisa e desenvolvimento da indústria durante este período: o mesmo permaneceu em 500 milhões de rúpias em 1986, respondendo por quase $2 \%$ do giro de vendas da indústria em comparação com menos de 1\% antes de 1970.

$\mathrm{O}$ ambiente da política facilitou a entrada livre de um grande número de produtores tanto do grande volume e formulação, sendo a maioria deles no setor desorganizado e de pequena escala. A estrutura de mercado resultante foi caracterizada por um número limitado de grandes unidades organizadas do setor usufruindo da parcela do leão do mercado, por um lado, e um número muito grande (milhares) de pequenos produtores, cada um produzindo uma fração microscópica do total de vendas da indústria. Isto sugeria uma grande variação na qualidade e preço de um medicamento no mercado e multiplicidade de formulações. Problemas de medicamentos espúrios e combinações irracionais foram um resultado natural deste fenômeno. Enquanto o ambiente da política favorecia pequenos produtores, a falta de regulamentos de qualidade adequados e mecanismos de controle frequentemente resultou no fornecimento de medicamentos ineficazes e inferiores ao ideal. Fora os desvios das normas de qualidade, a norma em si foi mantida com frequência em um nível baixo pela autoridade reguladora para incentivar pequenos produtores que não podem dispor de equipamentos sofisticados para diversos testes / ensaios. Com certeza, houve uma diferença notável nos parâmetros da qualidade aceitável dos medicamentos na Índia, em comparação com aquela do mundo desenvolvido. Mas a maioria dos medicamentos estava, agora, disponível na Índia a preços acessíveis, não obstante as variações na qualidade.

Como um resultado da estrutura da política, os MNCs ficaram relutantes em lançar seus novos medicamentos na Índia. Mas isto não privou os pacientes indianos das últimas descobertas de medicamentos sem muita demora no lançamento (Bhaduri \& Ray 2006; Ray \& Chakraborty 2007). As firmas indianas introduziram estes novos medicamentos no mercado usando processos não violadores, talvez com um período de tempo que ultrapassava, marginalmente, o período da demanda. Existem inúmeros exemplos: Ranitidine (Glaxo) e Amlodipine (Pfizer) são dois dos exemplos evidentes deste fenômeno.

\section{A nova ordem mundial após 1990: processo de reformas da Índia}

Em sintonia com uma ordem econômica internacional recém emergente, o processo de reformas econômicas da Índia começou no final da década de 1980 e início da década de 1990. A OMC foi a arquiteta principal da ampla estrutura desta nova ordem global, principalmente em relação ao livre comércio e a retirada das "distorções da política" em todas as dimensões da atividade econômica de um país. A idéia é pavimentar o caminho para fluxos internacionais orientados para o mercado e liberalizados de produtos, serviços, capital e tecnologia em uma estrutura multilateral. Ironicamente, porém, também são encontradas disposições para negociações bilaterais e ações unilaterais construídas na estrutura da OMC, especialmente quando ela serve ao interesse dos países desenvolvidos. As regulações e normas de produtos, medidas anti-dumping e outras medidas de salvaguarda são exemplos das disposições da OMC que podem ser usadas indevidamente (principalmente pelas nações desenvolvidas) para conter o espírito da liberalização comercial multilateral propagada pela OMC e os proponentes desta nova ordem mundial.

O processo de reforma da Índia começou com as reformas comerciais que procuravam reduzir, racionalizar e, eventualmente, eliminar todas as formas de restrições comerciais, tarifas, licenças de importação e exportação, restrições quantitativas e outras barreiras não-tarifárias. A redução e a retirada de subsídios acompanharam as reformas comerciais na Índia. As políticas para o investimento estrangeiro e tecnologias estrangeiras foram relaxadas. A FERA de 1973 foi modificada para a Lei de Administração de Câmbio Estrangeiro (FEMA) de 1999. O monitoramento de pagamentos para matéria-prima importada e know-how técnico foi desregulamentado, mas o RBI conservou a autoridade de monitoramento do pagamento do dividendo. A FEMA permite que os MNCs farmacêuticos aumentem suas participações na Índia até 74\%. A aprovação automática pode ser conferida para acordos de tecnologia estrangeira nas indústrias de alta prioridade até um pagamento de valor global de 10 milhões de rúpias, ou se os royalties forem inferiores a $5 \%$ das vendas domésticas ou $8 \%$ das exportações, sujeitos a um teto máximo. Para outras indústrias sem alta prioridade a permissão automática será dada de acordo com as mesmas 
diretrizes se não for necessário câmbio estrangeiro livre para quaisquer pagamentos.

A Lei de Patentes de 2005 foi uma baixa direta dos acordos da OMC. As características salientes do regime de patentes por vir estão resumidas abaixo.

- As patentes de produtos são permitidas em todos os campos da tecnologia com uma duração uniforme de 20 anos em produtos farmacêuticos, alimentícios e agroquímicos a partir da data da solicitação.

- As licenças compulsórias serão dadas pelo governo apenas no mérito de cada caso e seriam concedidas em caso de emergência nacional. Porém, o detentor de patente terá uma audiência e uma oportunidade para apresentar seu caso para proteção intelectual.

- Não haverá qualquer discriminação entre produtos importados e nacionais na medida em que a proteção da propriedade intelectual está em questão conforme a cláusula de tratamento nacional na OMC.

- Para as patentes de processo, o ônus da prova será da parte infratora. Isto contrasta com a exigência do regime de patentes inicial. Na Lei de Patentes de 1970, o ônus da prova era do inovador original.

Com a promulgação desta lei, a estrutura da política incentivando o desenvolvimento do processo através das atividades de engenharia reversa desaparece. Mas supõese que o sólido regime de produto incentive a pesquisa básica e de fronteiras na indústria.

Outros elementos do programa de ajustes estruturais seguidos pela Índia incluem as reformas industriais que levaram à abolição do licenciamento industrial, eliminação virtual dos regulamentos MRTP, desinvestimentos das unidades do setor público e desreserva e redução dos benefícios do setor de pequena escala.

Entre as iniciativas específicas da política para o setor farmacêutico, a DPCO de 1987 seguida pela DPCO de 1995 surgiram como marcos principais, reforçando o movimento da política para a liberalização. Ambas as políticas tinham como objetivo o descontrole progressivo dos preços dos medicamentos. É interessante observar a mudança clara na política no princípio declarado para controle dos preços dos medicamentos. Em oposição ao objetivo inicial de disponibilizar os medicamentos a preços acessíveis, a DPCO de 1995 afirma claramente que o objetivo é impedir o monopólio em qualquer segmento do mercado. Somente $40 \%$ do total das formas de dosagem concluídas permanecem sob controle de preço em 2001 , em comparação com 85-90\% em 1979.

A filosofia geral do regime da nova política está bem refletida nas Declarações das políticas de medicamentos de 1986, 1994 e 2003. As exigências para licenciamento de todos os medicamentos em grande quantidade e formulações estão extintas com algumas exceções anotadas. As restrições sobre a importação de grandes quantidades são amplamente retiradas. A política inicial para impedir o consumo cativo de grande quantidade é revertida. $O$ impulso principal é colocado sobre a qualidade do medicamento, reconhecendo a necessidade de monitorar e regular a qualidade e promover o uso racional de medica- mentos. Ela enfatiza a necessidade de implementação das Boas Práticas de Fabricação (GMP-Good Manufacturing Practices) para todas as unidades fabris.

Embora a IFI tenha continuado a se expandir tanto em termos de produção, quanto de comércio durante a década de $1990^{4}$, o ambiente da nova política impôs os principais desafios ao setor, que é evidente a partir do aumento dos preços dos medicamentos, redução do emprego e fechamentos das instalações de produção de muitas unidades, incluindo as das multinacionais. Como consequência, a IFI está passando por uma fase turbulenta de ajustes. A seguir tentaremos analisar este processo de ajuste para o segmento organizado da indústria. Isto não se destina a sugerir que os desafios às unidades de pequena escala são menos severos ou menos importantes, mas uma análise do setor de pequena escala constituiria um programa separado do estudo de pesquisa.

\section{Desafios e ajustes após a década de 1990: qualidade e pesquisa e desenvol- vimento (P\&D) como Pilares Gêmeos}

\section{Os desafios}

Os principais desafios impostos pelo regime da nova política de globalização e reformas na indústria farmacêutica indiana, especialmente aquelas no setor organizado, podem ser sintetizados conforme a seguir.

\section{Limites ao crescimento através do desenvolvimento de processo}

Com a introdução do novo regime de patentes, a estratégia de crescimento corporativo convencional, baseado no desenvolvimento de processo não violador para moléculas patenteadas para introduzir os últimos medicamentos no mercado indiano, adotada pela IFI até agora, não mais será uma opção viável. A engenharia reversa nos medicamentos patenteados chegará a uma parada completa, levantando um grande questionamento sobre a extensão em que a indústria farmacêutica pode explorar suas capacidades de desenvolvimento de processo adquiridas através de um esforço de pesquisa e desenvolvimento consciente durante o último quarto do século. A realização da engenharia reversa em medicamentos sem patente pode, é claro, continuar a dar a eles uma ponta no mercado genérico. De fato, um mercado de cerca de 50 bilhões de dólares americanos de produtos farmacêuticos sairá da patente nos próximos anos.

\section{Limites ao mercado genérico}

Considerando que os novos medicamentos se tornarão, agora, monopólio exclusivo da firma inovadora, acreditamos que o mercado genérico se tornará extremamente abarrotado tanto na Índia, quanto no mundo, já que todas as firmas não inovadoras terão que se dedicar a este mercado.

Outro limite sobre o desenvolvimento comercial baseado no mercado genérico pode ser colocado pelo alto índice de descobertas de novos medicamentos na década 
de 1990. Já que a maioria destes novos medicamentos não são "novos" no sentido de ter um uso terapêutico pioneiro, mas estão meramente substituindo os medicamentos existentes por melhor eficácia terapêutica e efeitos colaterais menores, a descoberta de novos medicamentos pode reduzir o tempo de vida dos medicamentos existentes. Isto, por sua vez, implica em um alto índice de obsolescência no mercado farmacêutico genérico.

O mercado farmacêutico global está se tornando progressivamente competitivo, tanto com relação ao preço, quanto com relação à qualidade. Mesmo com a liberalização do comércio, a OMC permite a imposição de normas e regulamentos de produtos para criar barreiras ao livre fluxo de comércio. Isto está sendo totalmente explorado pelos países desenvolvidos para proteger seus amplos mercados farmacêuticos das importações de baixo custo dos países em desenvolvimento. Portanto, as novas normas de qualidade de medicamentos estão sendo introduzidas no mundo todo, o que limitará ainda o escopo de acesso ao mercado genérico mundial. Com uma movimentação para a harmonização da qualidade, a qualidade dos medicamentos atuará como um parâmetro principal de sucesso, mesmo para as firmas indianas nos próximos anos.

\section{Os ajustes}

Para enfrentar estes desafios, a indústria indiana (setor organizado) está passando por uma fase principal de reestruturação e ajustes. Pretendemos analisar e capturar alguns deles, no entanto restringimos nossa análise a duas das principais dimensões do processo de ajuste. A primeira se relaciona à resposta da indústria indiana a um novo paradigma de qualidade dos medicamentos. A segunda olha para o papel mutante de $\mathrm{P} \& \mathrm{D}$ e tecnologia nesta nova era de globalização e reformas.

\section{Um novo paradigma de qualidade de medicamentos}

A qualidade do medicamento é um conceito multidimensional complexo. Primeiro e antes de tudo, qualidade sugere eficácia terapêutica e segurança. Um medicamento de alta qualidade deve ser eficaz e não deve produzir qualquer toxicidade ou efeito colateral. A este respeito, a bio-disponibilidade atua como um parâmetro importante da qualidade do medicamento. Um segundo parâmetro de qualidade comumente desejado pertence ao perfil de impureza e estabilidade dos ingredientes químicos. Outro parâmetro que afeta a pureza do produto é a contaminação durante o processo de produção. Não é importante apenas manter apenas a impureza em níveis mínimos, mas, também, deve-se observar a consistência no perfil de impureza especificado sobre todos os lotes da produção. A documentação detalhada de todas as fases da produção junto com as operações do controle de qualidade constituem uma dimensão adicionada da especificação da qualidade conforme ela cria uma memória institucional e torna todo o processo de produção transparente para todas as partes interessadas. ${ }^{5} \mathrm{O}$ terceiro conjunto de parâmetros de qualidade estipula que o processo de produção deve ser amigo do meio ambiente e não deve criar qualquer risco à saúde dentro e fora da unidade de produção. Os intermediários e excipientes do processo de produção também devem ser seguros e amigos do meio-ambiente. ${ }^{6}$

A importância relativa de cada um destes parâmetros diversos na especificação da qualidade final variaria de país para país, dependendo da composição de seu comitê farmacopeico e prioridades sócio-econômicas do governo. Isto resultou na divergência das exigências técnicas para especificação da qualidade e controle nos diferentes países, compelindo a indústria globalizada a replicar diversos procedimentos de teste, incluindo ensaios clínicos, a fim de comercializar novos produtos em diferentes países. Para superar este problema, os governos dos três maiores mercados farmacêuticos (Estados Unidos, Europa e Japão) iniciaram, em conjunto, um movimento para a harmonização da qualidade dos medicamentos através da Conferência Internacional sobre Harmonização (ICH) a partir do final da década de 1980. A Farmacopéia Americana (USP) dominou este movimento de harmonização com uma tendência embutida para normas progressivamente mais severas para perfil de impurezas através de instrumentação sofisticada e métodos analíticos.

Antes da década de 1990, a qualidade dos medicamentos na Índia era definida livremente e permanecia bem abaixo dos padrões internacionais. Isto não sugere que não havia qualquer produtor de alto nível mesmo durante este período. Mas os parâmetros de qualidade não receberam muita atenção por parte da indústria e autoridades reguladoras em geral. Mas na nova era da globalização, caracterizada por um regime estrito da IFI, uma fronteira de tecnologia que se movimentava rapidamente e um movimento para a harmonização internacional das normas de qualidade, as firmas terão que explorar o mercado internacional em crescimento para medicamentos genéricos, em particular o mercado americano. A entrada neste mercado altamente competitivo clama por exigências de qualidade rigorosas. Com certeza com a ameaça da $\mathrm{ICH}$, não apenas os Estados Unidos, mas todo o mercado global pode estar sujeito a normas de qualidade mais severas.

Nesta nova era, os fabricantes indianos têm que prestar atenção intensa ao conceito de qualidade de medicamento, que era, até agora, amplamente ignorado e adotar as seguintes mudanças operacionais e organizacionais:

- $O$ controle de qualidade deve ser muito mais rigoroso com parâmetros mais rigorosos e instrumentação sofisticada.

- Para as formulações, a qualidade dos ingredientes farmacêuticos ativos (API ou grande volume) se torna muito importante.

- As normas de alta qualidade conforme a definição multidimensional fornecida acima demanda uma modernização da produção e tecnologia de controle de qualidade.

- As dimensões ambientais da qualidade necessitam de uma atenção maior para o tratamento de efluentes e gerenciamento adequado de lixo usando métodos e equipamentos modernos.

- A documentação detalhada está se tornando uma faceta importante da produção e controle de qualidade. 
- Finalmente, a qualidade agregou uma nova dimensão a seu impulso de P\&D. As firmas estão tentando, agora, desenvolver novos métodos analíticos melhorados para especificação da qualidade e controle. Algumas firmas indianas já foram bem sucedidas no desenvolvimento de métodos melhores, que foram incorporados nas normas de qualidade globais, como a USP e a EP. De certa forma, os participantes indianos contribuíram, assim, para mudanças externas nas fronteiras globais da qualidade dos medicamentos.

A maioria destes elementos de qualidade acarreta uma automação maior no processo de produção. Em muitos casos, isto exige uma inspeção completa da configuração da planta para instalar maquinaria sofisticada (com frequência importada) e equipamentos para a produção e controle de qualidade.

Da "Pesquisa e Desenvolvimento Orientada para o Negócio" ao "Negócio Orientado para a Pesquisa e Desenvolvimento"

A capacidade tecnológica da indústria farmacêutica indiana pode ser classificada em três grupos amplos:

- Capacidades de desenvolvimento de processo (medicamento em grandes quantidades) - violadoras e não-violadoras.

- Capacidades de desenvolvimento de produto (formulações) - formas de dosagem convencional (CDF), sistemas de entrega de medicamentos novos (NDDS) de primeira e segunda gerações (NDDS 1, NDDS2 respectivamente) e métodos analíticos para qualidade.

- Desenvolvimento de novo medicamento (NDDR).

A indústria começou com capacidades de desenvolvimento de produtos simples no CDF e começou a produzir a formulação a partir de medicamentos importados em grande quantidade. Finalmente, conforme o negócio se expandia, a indústria começou a fazer um esforço explícito para a aquisição de capacidade tecnológica de desenvolvimento de processo após a década de 1970 com o objetivo de desenvolver processos minimizadores de custo não-violadores. No final da década de 1980, a IFI atingiu novos patamares da tecnologia de processo, que atuou como a força motriz chave para a revolução farmacêutica indiana; até o momento em que a evolução da capacidade tecnológica seguiu a trajetória convencional do desenvolvimento tecnológico resumido na literatura econômica padrão. ${ }^{7}$

Porém, na década de 1990, encontramos uma ênfase renovada no desenvolvimento de produtos, mas desta vez, não sobre o CDF, mas sobre NDDSI (formas de dosagem de liberação sustentada / controlada) e sobre NDDS2 (formas de dosagem de liberação alvo) empreendido apenas por algumas firmas. Este movimento é ditado pelo ambiente da nova política pelo qual a expansão comercial através do desenvolvimento de processos não-violadores será severamente limitada. NDDS1 e NDDS2, suprindo as necessidades especializadas de paciente demasiadamente delicado, são sinais claros de uma movimentação para o negócio orientado pela $\mathrm{P} \& \mathrm{D}$ - estes novos desenvolvimentos tecnológicos tentam abrir novas dimensões do negócio farmacêutico na Índia.

As capacidades avançadas de desenvolvimento de produtos (NDDS e métodos analíticos) pavimentaram o caminho para a pesquisa de descoberta de novos medicamentos (NDDR) na Índia. As competências existentes em química junto com o fortalecimento da habilidade de biologia (biologia molecular e estrutural, em particular) existentes para a pesquisa NDDS e experiência no manuseio de equipamentos sofisticados facilitaram a NDDR na Índia. Porém, a natureza, o processo e as etapas da NDDR na Índia refletem normalmente a evolução da capacidade tecnológica de um LDC típico com capacidades de pesquisa, financeiras e de tomada de risco limitadas. A NDDR do tipo me-too na Índia, focando predominantemente na invenção ao redor de um inibidor existente para um dado alvo, é muito menos arriscada e menos onerosa do que encontrar um novo alvo. Ela foi principalmente orientada pelas competências existentes e capacidades ao invés de se arriscar em novas áreas de desenvolvimento de capacidade e investimentos de P\&D.

Dado que a capacidade indiana ainda não está madura o suficiente para concorrer, no mesmo nível, com os participantes globais na pesquisa da descoberta de novos medicamentos, o regime da IFI na Índia continua um tanto protetor. A Lei de Patentes de 2005, dentro das diretrizes TRIPS, manteve os critérios de patenteabilidade um tanto rigorosos, limitando a concessão de patentes para substâncias farmacêuticas para novas entidades químicas e novas entidades médicas que envolviam uma ou mais etapas inventivas. Como tal, outras inovações farmacêuticas (incluindo a combinação de medicamentos conhecidos, reclamações de novos usos de medicamentos existentes etc.) estão excluídos da concessão de patentes na Índia. A idéia é impedir a perenidade de patentes pelos grandes participantes globais ocupados na pesquisa de descoberta de novos medicamentos e incentivar a capacidade da Índia para inventar ao redor e chegar a medicamentos do tipo me-too. Embora a Índia tenha atingido patamares impressionantes de maturidade tecnológica em produtos farmacêuticos, ainda tem que chegar nas fronteiras globais da pesquisa de descoberta de medicamentos de ponta. Isto somente pode ser alcançado através do esforço tecnológico sustentado e P\&D contínuos. Com certeza, no cenário pós-reformas, a P\&D exercerá o papel central na manutenção de uma trajetória bem sucedida de crescimento e desenvolvimento da indústria farmacêutica indiana. A indústria agora será caracterizada pelo negócio orientado pela P\&D ao invés da P\&D orientada pelo negócio.

\section{Notas}

1. Este trabalho se reporta a um dos meus trabalhos iniciais (Ray 2004, 2005).

2. India in Business website do Ministério das Relações Exteriores (Divisão de Promoção de Investimentos e Tecnologia (ITP)), Governo da Índia. http://www.indiainbusiness.nic.in/industry-infrastructure/industrial-sectors/drug-pharma.htm 
3. Política Farmacêutica Nacional de 2006, Ministério dos Químicos e Petroquímicos, Governo da Índia.

4. Ver Key Statistics, OPPI (www.indiaoppi.com/keystat. htm) para obter informações.

5. Consequentemente houve uma tendência crescente para a automação da tecnologia da produção para eliminar o registro de variações, toque humano e produzir lotes consistentes com documentação computadorizada detalhada.

6. A automação progressiva pode tomar conta dos problemas de contato "perigoso" da mão-de-obra com ingredientes químicos e processos nocivos. Um outro modo de resolver o problema é substituir os processos químicos por processos biotecnológicos conforme é feito nas nações desenvolvidas.

7. Ver Katz (1984, 87), Lall (1987).

\section{Referências Bibliográficas}

Bhaduri S, Ray AS. A game theoretic model of drug launch in India. Health Economics, Policy and Law. 2006; 1(1).
Katz J. Domestic technological innovations and dynamic comparative advantage. J Devel Econ. 1984; 16:13-37.

Katz J. Domestic technology generation in LDCs: a review of research findings. In: Katz JM, editor. Technology generation in Latin American manufacturing industries. London: Macmillan; 1987.

Lall S. Learning to Industrialise: the acquisition of technological capability by India. London: Macmillan; 1987.

Ray AS. The changing structure of R\&D incentives in India: the pharmaceutical sector. Sci Technol Society. 2004; 9(2).

Ray AS. The Indian pharmaceutical industry at crossroads: implications for India's health care. In: Bagchi A, Soman K, editors. Maladies, preventives and curatives: debates in public health in India, New Delhi: Tulika Books; 2005.

Ray AS, Chakravorty M. Access to new drugs in India: Implications of TRIPS" In: Agarwal M, Ray AS, editors. Globalisation and the millennium development goals: negotiating the challenge. New Delhi: Social Science Press; 2007.

\section{Sobre o autor}

\section{Amit Shovon Ray}

O Professor Ray é professor de Economia no Centro para Comércio e Desenvolvimento Internacionais, Escola de Estudos Internacionais, Jawaharlal Nehru University, Nova Deli. Atualmente, ele está saindo da JNU a convite para uma Cadeira (Professor de Concorrência e Tecnologia Comercial) no Conselho Indiano para Pesquisas sobre Relações Econômicas Internacionais (ICRIER), Nova Deli. Ele foi educado em Presidency College, Calcutá, e na Universidade de Oxford. Ele manteve cargos de ensino e pesquisa nas principais Universidades e Instituições na Índia e no exterior, incluindo o Instituto de Economia e Estatística da Universidade de Oxford, Instituto de Pesquisa de Política Alimentícia Internacional (Washington DC), Jawaharlal Nehru University (Nova Deli), Universidade de Calcutá (Kolkata) e Instituto Indiano de Tecnologia (Deli). Ele é Associado da Real Sociedade para a Promoção da Saúde (FRSH, Londres) e Membro da Comissão Independente sobre Desenvolvimento e Saúde na Índia (ICDHI, Nova Deli). Ele foi Consultor de diversos órgãos nacionais e internacionais, incluindo a Comissão de Planejamento (Governo da Índia), Banco Mundial, UNCTAD, Associação Voluntária de Saúde da Índia (VHAI, Nova Deli) e Conselho Indiano para Pesquisa sobre Relações Econômicas Internacionais (ICRIER, Nova Deli). O Professor Ray é um economista do desenvolvimento e pesquisou sobre questões de tecnologia e Pesquisa e Desenvolvimento, OMC, direitos de propriedade intelectual, FDI comércio em serviços, indústria farmacêutica e cuidados de saúde. Ele publicou extensamente, tanto nacionalmente quanto internacionalmente, e apresentou sua pesquisa em seminários e conferências em diversas partes do mundo - Brasil, Canadá, China, Índia, Paquistão, Espanha, Suíça, Taiwan, Tailândia, Reino Unido e Estados Unidos. 